\title{
Molecular Structure and Surface Accumulation Dynamics of Hyaluronan at the Water-Air Interface
}

\author{
Carolyn J. Moll,* Giulia Giubertoni, Lennard van Buren, Jan Versluis, Gijsje H. Koenderink,
} and Huib J. Bakker*

Cite This: Macromolecules 2021, 54, 8655-8663

Read Online

ABSTRACT: Hyaluronan is a biopolymer that is essential for many biological processes in the human body, like the regulation of tissue lubrication and inflammatory responses. Here, we study the behavior of hyaluronan at aqueous surfaces using heterodyne-detected vibrational sum-frequency generation spectroscopy (HD-VSFG). Low-molecular-weight hyaluronan $(\sim 150 \mathrm{kDa})$ gradually covers the water-air interface within hours, leading to a negatively charged surface and a reorientation of interfacial water molecules. The rate of surface accumulation strongly increases when the bulk concentration of low-molecular-weight

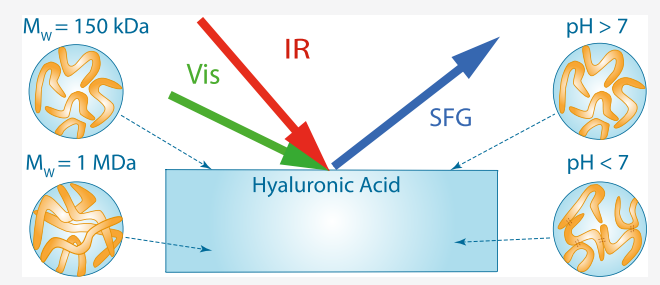
hyaluronan is increased. In contrast, high-molecular-weight hyaluronan (>1 MDa) cannot be detected at the surface, even hours after the addition of the polymer to the aqueous solution. The strong dependence on the polymer molecular weight can be explained by entanglements of the hyaluronan polymers. We also find that for low-molecular-weight hyaluronan the migration kinetics of hyaluronan in aqueous media shows an anomalous dependence on the $\mathrm{pH}$ of the solution, which can be explained from the interplay of hydrogen bonding and electrostatic interactions of hyaluronan polymers.

\section{INTRODUCTION}

Glycosaminoglycans (GAGs) are charged biopolymers (polyelectrolytes), which play an important role in various biological processes in our body, ranging from anticoagulation to immune response to external pathogens. ${ }^{1}$ Among all of the glycosaminoglycans, hyaluronan is arguably one of the most important and most studied. Hyaluronan is the structurally simplest GAG and regulates biological functions like tissue lubrication and inflammatory responses. ${ }^{2-5} \mathrm{New}$ hyaluronan is constantly synthesized, and a defective regulation of hyaluronan production can lead to severe diseases. Alterations in the concentration and molecular weight of hyaluronan have, for instance, been linked to cancer initiation, metastasis, therapy resistance, and arthritic diseases. ${ }^{6-10}$ For example, it has been found that in healthy individuals the synovial fluid, which guarantees the correct lubrication between the knee cartilages, contains a concentration of $1.3-4 \mathrm{mg} / \mathrm{mL}$ of hyaluronic acid (HA) with a high molecular weight $\left(\mathrm{HA}_{\mathrm{HMW}}\right)$ of $1.5-1.8$ MDa. ${ }^{8}$ In the case of patients affected by arthritic diseases, the concentration of $\mathrm{HA}_{\mathrm{HMW}}$ decreases to $0.1-1.3 \mathrm{mg} / \mathrm{mL}$, while the concentration of low-molecular-weight hyaluronic acid $\left(\mathrm{HA}_{\mathrm{LMW}} \sim 100-150 \mathrm{kDa}\right)$ increases. $^{8-10}$ Changing the ratio between $\mathrm{HA}_{\mathrm{HMW}}$ and $\mathrm{HA}_{\mathrm{LMW}}$ can influence the viscoelasticity of the synovial fluid, which can have drastic effects on joint lubrication. ${ }^{8}$ Furthermore, because of its biocompatibility, hyaluronan is widely used in biomedicine to design hydrogels with tailored applications. ${ }^{11}$ The polymer also forms important structural component of artificial tears, or eye drops, to facilitate the lubrication and hydration of contact lenses. ${ }^{12,13}$
The outstanding physiological relevance and the wide application of hyaluronan have led to numerous studies of its microscopic and macroscopic properties in the bulk. ${ }^{14-21}$ Many of these studies were aimed at finding the connection between the macroscopic and molecular properties, which are dictated by molecular weight and concentration, and their impact on biological functions. However, up to now, the interfacial properties of hyaluronan have only been investigated by macroscopic surface tension measurements. ${ }^{22,23}$ Until now a detailed molecular picture of the surface of aqueous hyaluronan solutions is completely missing. A more detailed knowledge of these molecular-scale properties can be helpful in acquiring a better understanding of the special interfacial properties of aqueous hyaluronan solutions, like its lubrication behavior and its biochemical interactions.

We use conventional vibrational sum-frequency generation (VSFG) spectroscopy and heterodyne-detected vibrational sum-frequency generation (HD-VSFG) spectroscopy to study the surface propensity and molecular structure of aqueous HA solutions at the water-air interface. VSFG techniques are highly surface specific and, therefore, ideally suited for the study of the molecular-scale properties of polymers adsorbed at

Received: February 15, 2021

Published: September 16, 2021 

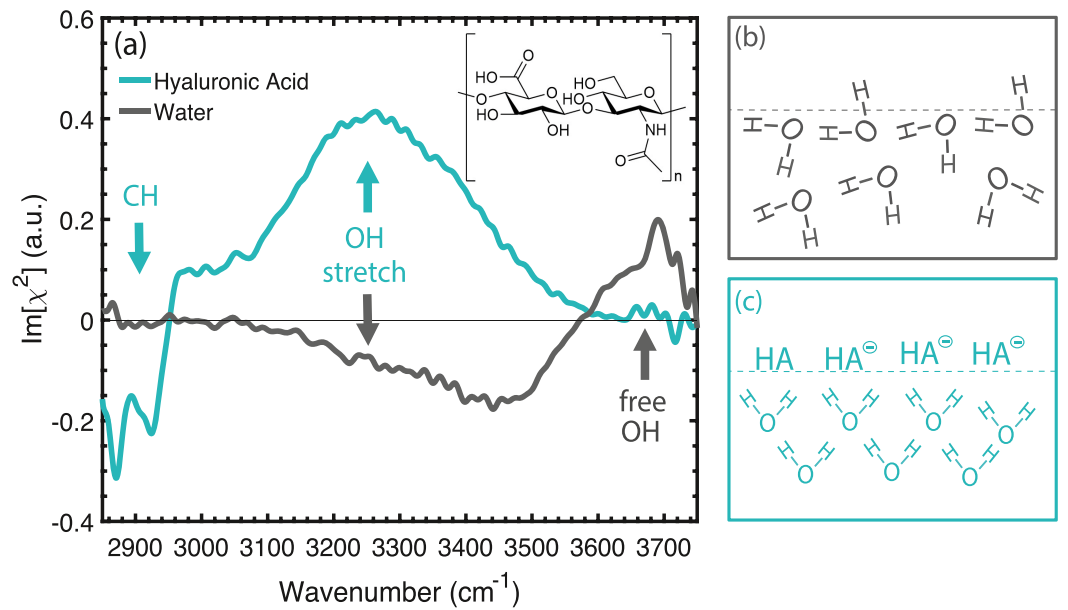

Wavenumber $\left(\mathrm{cm}^{-1}\right)$

Figure 1. (a) $\operatorname{Im}\left[\chi^{(2)}\right]$ spectra of pure water (gray) and a low-molecular-weight $(100-150 \mathrm{kDa})$ hyaluronan solution $\left(\mathrm{HA} \mathrm{LMW}_{\mathrm{LM}}, 4.5 \mathrm{mg} / \mathrm{mL}, 60 \mathrm{~min}\right.$ after placing the sample in the VSFG setup, cyan) at the water-air interface, measured in SSP polarization configuration (s-SFG, s-VIS, p-IR). The HA solutions have a $\mathrm{pH}$ of 7.4 regulated with a phosphate buffer, as described in the text. The inset shows a schematic of the repeating molecular structure of HA. Schematic of the orientation of water molecules (b) at the neat water surface and (c) at the surface of a hyaluronan solution.

interfaces, providing information on the conformation and solvent interactions of the molecules of interest. ${ }^{24-27} \mathrm{We}$ find that the kinetics of the adsorption process strongly depends on the molecular weight and the bulk concentration and shows an extremely strong and anomalous dependence on the ionic strength and the $\mathrm{pH}$ of the solution. The HD-VSFG measurements in this study specifically target the water-air interface, but the findings may also provide new insights in the interfacial properties of hyaluronan at aqueous interfaces more closely related to biological processes, e.g., lubrication.

\section{METHODS}

Sample Preparation. The hyaluronic acid sodium salt in powder form from Streptococcus equi bacteria is purchased from SigmaAldrich, Czech Republic (>1 MDa) and from Biomedical Lifecore $(\sim 150 \mathrm{kDa})$. In preparing $\mathrm{HA}$ solutions, we use water from a Millipore Nanopure system $(18.2 \mathrm{M} \Omega \mathrm{cm})$. Both types of HA are used without further purification. The HA solutions with low molecular weight and high molecular weight are prepared at room temperature at least 2 and $24 \mathrm{~h}$ before the measurement, respectively, to ensure complete solvation of the biopolymer. The HA solutions are stored for at most 1 month at a temperature of $4{ }^{\circ} \mathrm{C}$. All HA solutions are mixed with a vortex once more directly before the measurement to ensure a uniform solution. In concentration-dependent measurements, we used a sodium phosphate buffer $(137 \mathrm{mM} \mathrm{NaCl}, 10 \mathrm{mM}$ $\mathrm{Na}_{2} \mathrm{HPO}_{4}$, and $2.7 \mathrm{mM} \mathrm{KCl}$ ) as a solvent to keep the $\mathrm{pH}$ constant at $\mathrm{pH} 7.4$ and the ionic strength close to that of the synovial fluid, which contains $155 \mathrm{mM}$ of sodium chloride. ${ }^{28}$ In $\mathrm{pH}$-dependent measurements, the solution contained a constant concentration of $150 \mathrm{mM}$ of $\mathrm{NaCl}$, and the $\mathrm{pH}$ was regulated by adding $\mathrm{NaOH}$ and $\mathrm{HCl}$ to the solution. To perform measurements with different salt concentrations, we varied the $\mathrm{NaCl}$ concentration from 0 to $300 \mathrm{mM}$ in the $\mathrm{HA}$ solution. Additionally, all measurements are taken in a custom-built sample cell covered by a calcium fluoride window to prevent solvent evaporation. The sample cell is made of Teflon and can hold a sample solution with a volume of up to $4 \mathrm{~mL}$. A schematic picture of the sample cell can be found in the Supporting Information (Figure S1). Since the sample cell has a diameter of $3.5 \mathrm{~cm}$ and the lateral spatial resolution of our measurement is $100 \mu \mathrm{m}$, we effectively have a flat air-liquid interface.

Conventional and Heterodyne-Detected Vibrational SumFrequency Generation (VSFG and HD-VSFG). The technique of HD-VSFG was initially demonstrated by Shen and co-workers in 2005 and successfully used in a large number of surface studies. ${ }^{29-31}$ Here, we give a brief description of HD-VSFG, while a detailed explanation can be found in previous publications. ${ }^{32,33}$ For both conventional VSFG and HD-VSFG, we use an amplified Ti:Sapphire laser system $(1 \mathrm{kHz}, 35 \mathrm{fs}, 3.5 \mathrm{~mJ} /$ pulse $)$ to generate a narrow-band $800 \mathrm{~nm}$ beam and a tuneable mid-infrared beam using an optical parametric amplifier (OPA). The $800 \mathrm{~nm}$ pulse has a duration of a few picoseconds, and the mid-infrared pulse has a duration of $\sim 100 \mathrm{fs}$. For conventional VSFG, these beams are directly spatially and temporally overlapped at the sample surface generating a sum-frequency generation (SFG) signal. The SFG signal of the sample is detected with a thermoelectrically cooled electron multiplied charged-coupled device (EMCCD, Andor Technologies) and gives us the intensity of the vibrational modes of the sample at the surface. In the case of HDVSFG, the more advanced technique, the $800 \mathrm{~nm}$ beam, and the midinfrared beam are first spatially and temporally overlapped at the surface of a local oscillator (LO, gold mirrror) to generate a SFG signal. The $800 \mathrm{~nm}$ beam, the mid-infrared beam, and the SFG signal are sent to a concave mirror. Before the beams are focused on the sample surface, the SFG signal of the LO is sent through a silica plate where it is delayed in time $(\sim 1.6 \mathrm{ps})$. The $800 \mathrm{~nm}$ and mid-infrared beam generate a second SFG signal at the sample surface. Both the SFG signal of the LO and of the sample are sent to the EMCCD, where the interference spectrum of the two SFG signals is recorded. From the interference spectrum, the real (Re) and the imaginary (Im) spectra can be extracted, providing direct information on the orientation of the vibrational transition dipole moments at the surface. This HD-VSFG spectrum thus provides unique information on the absolute orientation of molecules at the surface. ${ }^{32}$ To normalize for the spectral intensity of the mid-infrared beam, we measure for both techniques as a reference the SFG signal from a zcut quartz crystal. The typical acquisition time of a VSFG and a HDVSFG spectrum is 600 and $120 \mathrm{~s}$, respectively. Furthermore, with VSFG and HD-VSFG, we probe the sample over a very small depth, corresponding to a few molecular layers. ${ }^{34}$ The lateral spatial resolution of the technique is defined by the size of the foci and is approximately $100 \mu \mathrm{m}$.

\section{RESULTS AND DISCUSSION}

In Figure 1, we present the comparison between the HDVSFG spectra of pure water and low-molecular-weight hyaluronic acid $\left(\mathrm{HA}_{\mathrm{LMW}} \sim 100-150 \mathrm{kDa}\right)$ dissolved in buffer solution $(\mathrm{pH}=7.4)$, measured $60 \mathrm{~min}$ after placing the sample in the VSFG setup. The HA solution is mixed just before the measurement; therefore, we can define for all of the reported measurements time zero as the time when the sample is positioned in the VSFG setup. The measurement is taken in 
(a)

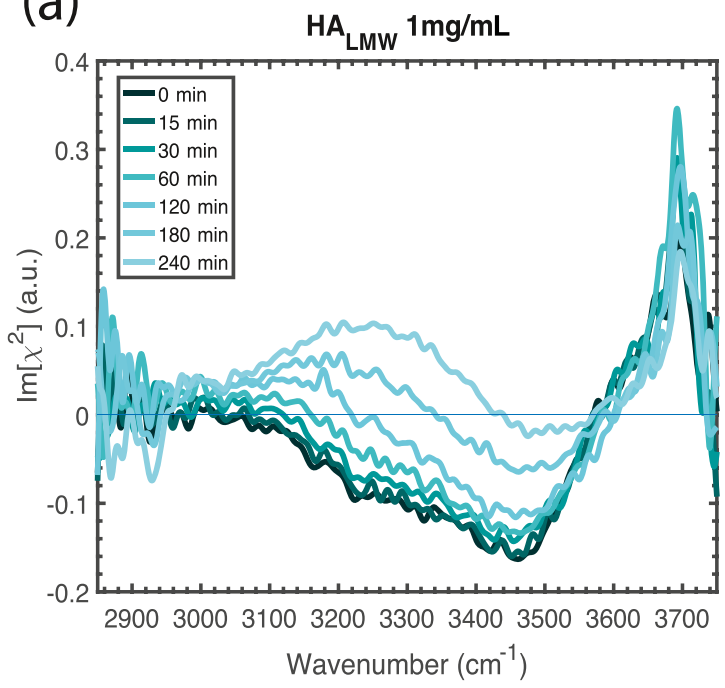

(c)

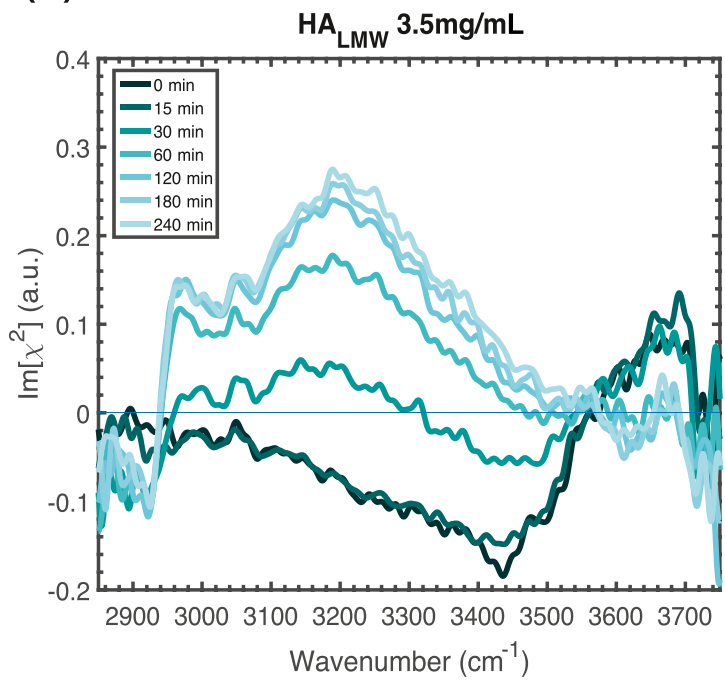

(b)

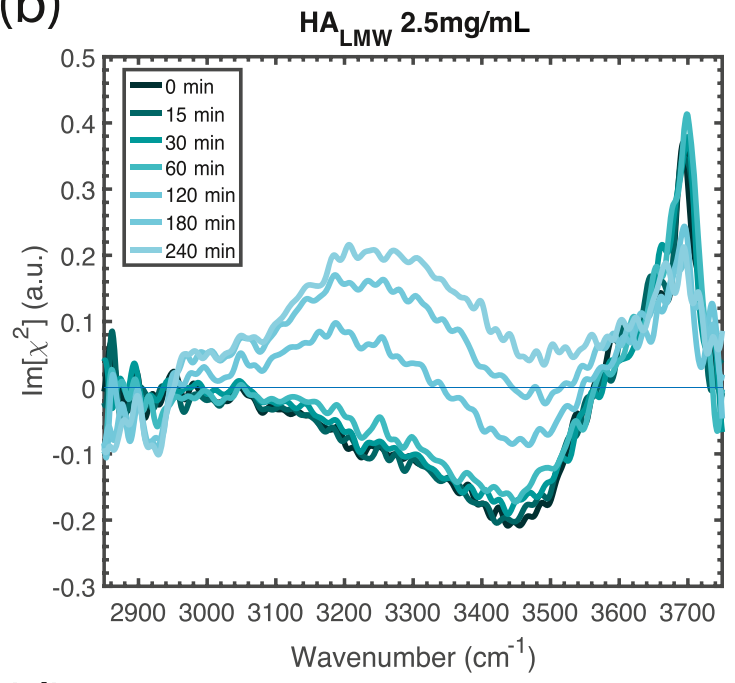

(d)

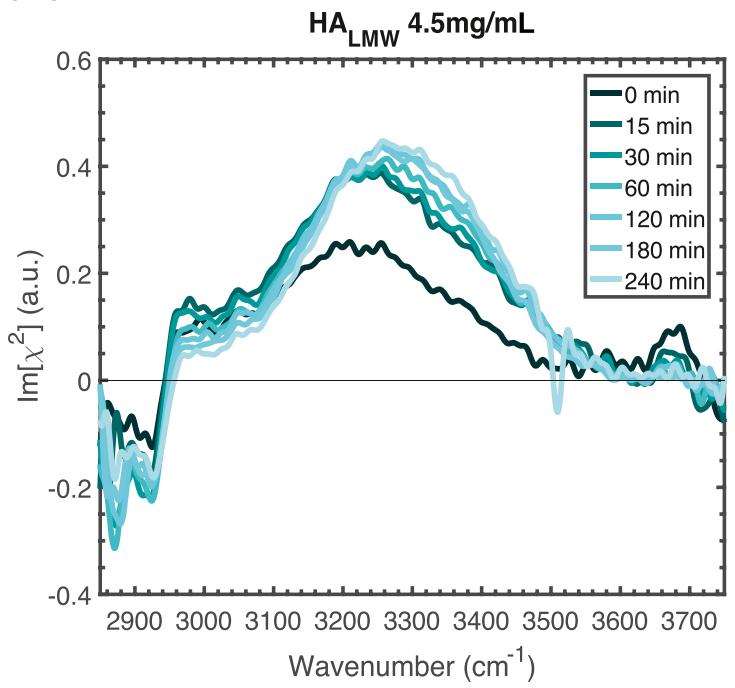

Figure 2. $\operatorname{Im}\left[\chi^{(2)}\right]$ spectra of aqueous $\mathrm{HA}_{\mathrm{LMW}}$ solutions with concentrations of (a) $1 \mathrm{mg} / \mathrm{mL},(\mathrm{b}) 2.5 \mathrm{mg} / \mathrm{mL}$, (c) $3.5 \mathrm{mg} / \mathrm{mL}$, and (d) $4.5 \mathrm{mg} / \mathrm{mL}$ at the water-air interface in a time range of $0-240 \mathrm{~min}$. The measurements were taken in SSP polarization configuration (s-SFG, s-VIS, p-IR) and the $\mathrm{pH}$ is regulated with phosphate buffer to 7.4, as described in the text. For all $\mathrm{HA}_{\mathrm{LMW}}$ solutions, it can be observed that two signals in the $\mathrm{CH}$ region appear and the broad water band is changing sign. For low concentrations of hyaluronic acid ( 1 and $2.5 \mathrm{mg} / \mathrm{mL})$, the signal of the free $\mathrm{OH}$ at $3700 \mathrm{~cm}^{-1}$ decreases over time, while for high concentrations $(3.5$ and $4.5 \mathrm{mg} / \mathrm{mL}$ ), it vanishes completely.

SSP polarization configuration (s-SFG, s-VIS, p-IR). The presented $\operatorname{Im}\left[\chi^{(2)}\right]$ spectrum of pure water is in excellent agreement with results obtained in previous studies. ${ }^{31,35,36}$ In the range between 3100 and $3550 \mathrm{~cm}^{-1}$, the $\operatorname{Im}\left[\chi^{(2)}\right]$ water spectrum shows a broad negative band originating from the $\mathrm{OH}$ stretch vibrations of water molecules that form hydrogen bonds to other water molecules. Additionally, the spectrum shows a narrow peak at $3700 \mathrm{~cm}^{-1}$. This highly surface-specific feature at $3700 \mathrm{~cm}^{-1}$ is assigned to the $\mathrm{OH}$ stretch vibrations of non-hydrogen-bonded $\mathrm{OH}$ groups that stick out of the surface. The sign of the $\operatorname{Im}\left[\chi^{(2)}\right]$ spectrum of the stretch vibration of water is directly related to the orientation of the vibrational transition dipole moment. A positive sign of $\operatorname{Im}\left[\chi^{(2)}\right]$ of the $\mathrm{OH}$ stretch vibrations corresponds to a net orientation with the hydrogen atoms pointing toward the air (up), while a negative sign of $\operatorname{Im}\left[\chi^{(2)}\right]$ corresponds to the hydrogen atoms pointing into the liquid (down).

The $\operatorname{Im}\left[\chi^{(2)}\right]$ spectrum of the HA solution differs strongly from the spectrum of pure water. In the region of 2850-3000 $\mathrm{cm}^{-1}$, we find two narrow features that are associated with the $\mathrm{CH}$ vibrations of the $\mathrm{HA}$ molecules. Based on previous work we assign the two negative bands centered at 2880 and 2940 $\mathrm{cm}^{-1}$ to the symmetric stretch vibration of the methyl group $\left(\mathrm{CH}_{3}\right)$ and its Fermi resonance overlapping with the symmetric stretch vibration of the methylene group $\left(\mathrm{CH}_{2}, \mathrm{SS}\right)$, respectively. ${ }^{25,31}$ The positive band at $\sim 2975$ $\mathrm{cm}^{-1}$ is assigned to the asymmetric stretch of the methylene group $\left(\nu_{\mathrm{CH}_{2}, \mathrm{AS}}\right) \cdot{ }^{31,37}$ The negative sign of the $\nu_{\mathrm{CH}_{2}, \mathrm{SS}}$ and the positive sign of $\nu_{\mathrm{CH}_{2}, \mathrm{AS}}$, show that the methylene groups have a net orientation with the $\mathrm{CH}$ bonds pointing toward the air phase. The negative sign of the $\nu_{\mathrm{CH}_{3}}$ band suggests that the methyl groups are also pointing preferentially toward air. ${ }^{25,31}$ Between 3100 and $3550 \mathrm{~cm}^{-1}$, we observe a broad signal that is associated with the $\mathrm{OH}$ stretch vibrations of interfacial water molecules. The positive sign of the broad $\mathrm{OH}$ stretch signal shows that the interfacial water molecules have a net orientation with the $\mathrm{OH}$ groups pointing toward the interface. 

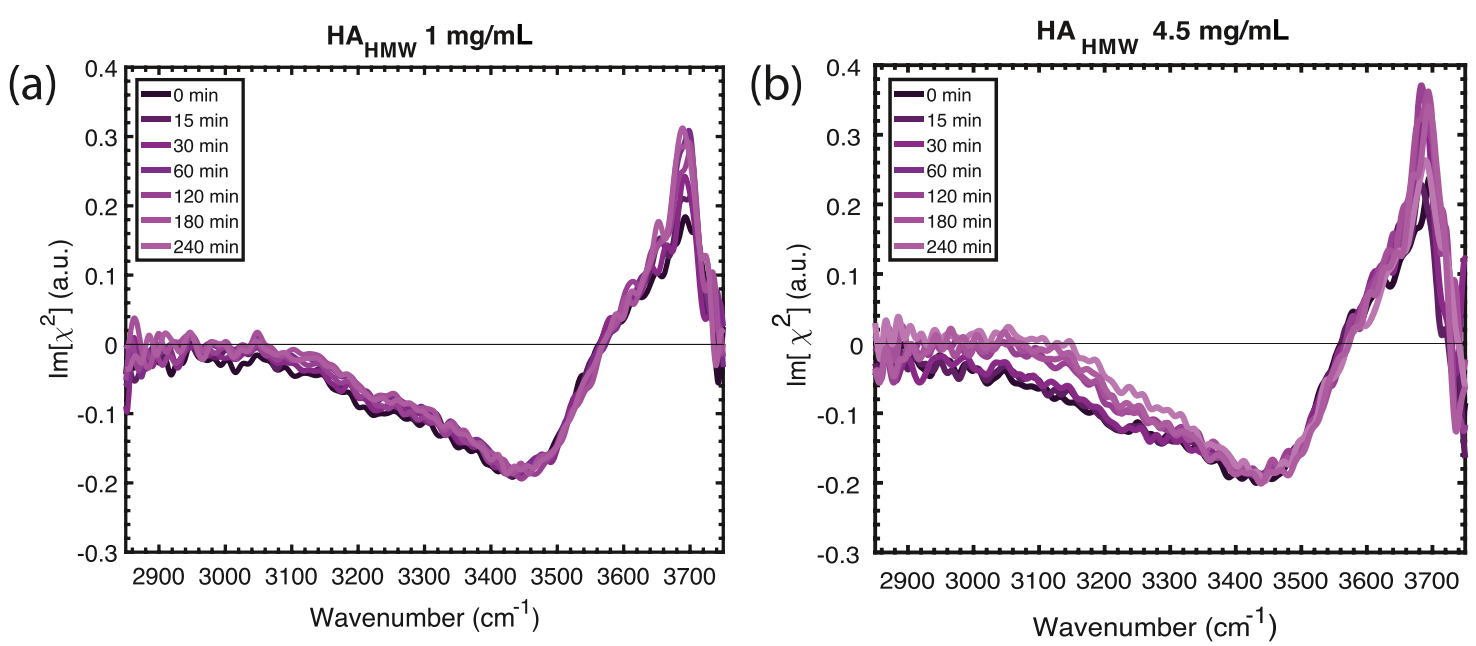

Figure 3. $\operatorname{Im}\left[\chi^{(2)}\right]$ spectra of high-molecular-weight hyaluronan $\left(\mathrm{HA}_{\mathrm{HMW}}\right)$ solutions with concentrations of $(\mathrm{a}) 1 \mathrm{mg} / \mathrm{mL}$ and $(\mathrm{b}) 4.5 \mathrm{mg} / \mathrm{mL}$ in a time frame of $0-240 \mathrm{~min}$. The HA solutions have a $\mathrm{pH}$ of 7.4 regulated with a phosphate buffer.

The change in net orientation of water molecules compared to pure water indicates that the surface is negatively charged, ${ }^{31}$ as a result of the accumulation of HA molecules at the surface. Because of its $\mathrm{pK}_{\mathrm{a}}$ of 2.9, hyaluronan is expected to be completely deprotonated in the bulk and thus negatively charged at $\mathrm{pH} 7 .^{15}$ In Figure $1 \mathrm{~b}, \mathrm{c}$, we show a schematic that shows the orientation of water molecules for pure water and $\mathrm{HA}_{\mathrm{LMW}}$ solution at the surface. The vanishing of the nonhydrogen-bonded $\mathrm{OH}$ can be explained by the complete surface coverage by HA molecules.

It should be noted that $\mathrm{HA}_{\mathrm{LMW}}$ only comes to the surface if a sufficient amount of ions are present in the solution (Figures S2 and S3). This observation can likely be explained from the competition between ions and HA for solvent molecules. Salt ions interact strongly with water molecules, ${ }^{38,39}$ thereby excluding the polymers from the bulk and pushing the polymer chains toward the surface. An additional effect may be the screening of the favorable interaction of the carboxylate anion groups of hyaluronan with water by the sodium ions.

Effect of the Hyaluronan Concentration on Its Accumulation at the Surface. Figure $2 a-d$ shows the $\operatorname{Im}\left[\chi^{(2)}\right]$ spectra of $\mathrm{HA}_{\mathrm{LMW}}$ solutions with different concentrations in the time range of $0-240 \mathrm{~min}$. In Figure $2 \mathrm{a}$, the $\operatorname{Im}\left[\chi^{(2)}\right]$ spectra of a $\mathrm{HA}_{\mathrm{LMW}}$ solution with a concentration of 1 $\mathrm{mg} / \mathrm{mL}$ is presented. It can be observed that at $0 \mathrm{~min}$ the spectrum of the $\mathrm{HA}_{\mathrm{LMW}}$ solution looks identical to that of a neat water surface. Over time, we observe that the sign of the broad water $\mathrm{OH}$ stretch band at $3100-3550 \mathrm{~cm}^{-1}$ changes from negative to positive. This sign change reflects a change in the net orientation of the water molecules. At $0 \mathrm{~min}$, the hydrogen atoms of the water molecules have a net orientation toward the bulk. Gradually, the water molecules are orienting more and more with their hydrogen atoms toward the surface, which is due to the accumulation of negatively charged HA molecules at the surface. For higher concentrations (Figure $2 \mathrm{~b}-\mathrm{d}$ ) of $2.5-4.5 \mathrm{mg} / \mathrm{mL}$, we additionally observe that the response of non-hydrogen-bonded $\mathrm{OH}$ vibrations centered at $3700 \mathrm{~cm}^{-1}$ decreases and eventually vanishes completely, and that in the $\mathrm{CH}$ region, two peaks appear that can be assigned to the methyl group $\left(\nu_{\mathrm{CH}_{3}}\right)$ and the methylene group $\left(\nu_{\mathrm{CH}_{2}, \mathrm{SS}}\right)$ of the HA molecules. ${ }^{25,31}$ We also find that the peak height of non-hydrogen-bonded molecules centered at $3700 \mathrm{~cm}^{-1}$ reduces to $\sim 65 \%$ of its original value simultaneous with the first appearance of the $\mathrm{CH}$ vibrations of the polymer backbone. Hence, we conclude that to get a clear VSFG signal of HA molecules, their surface coverage needs to be $\sim 35 \%$, as the HD-VSFG signal is proportional to the surface density. The maximum studied bulk concentration is $4.5 \mathrm{mg} / \mathrm{mL}$, which corresponds to $\sim 0.5 \%$, which implies that the final surface concentration is much higher than the bulk concentration, showing that over time HA accumulates at the surface. The difference between the $\operatorname{Im}\left[\chi^{(2)}\right]$ spectrum of $\mathrm{HA}_{\mathrm{LMW}}$ solutions and that of pure water becomes more pronounced with increasing polymer concentration. Furthermore, it is observed that spectral changes occur faster with increasing $\mathrm{HA}_{\mathrm{LMW}}$ concentration. Consistent with this notion is that increasing the bulk concentration of the $\mathrm{HA}_{\mathrm{LMW}}$ solution leads to faster mass transport diffusion ${ }^{40}$ and thus a faster accumulation of HA polymers at the surface. ${ }^{41} \mathrm{We}$ also performed surface tension measurements of $\mathrm{HA}_{\mathrm{LMW}}$ in a sodium phosphate buffer $\left(137 \mathrm{mM} \mathrm{NaCl}, 10 \mathrm{mM} \mathrm{Na} \mathrm{HPO}_{4}, 2.7 \mathrm{mM} \mathrm{KCl}\right.$ ) with a $\mathrm{pH}$ of 7.4. As shown in Figures S4 and S5 of the Supporting Information, we observe no changes in the surface tension over time for solutions containing different concentrations of $\mathrm{HA}_{\mathrm{LMW}}$. It is more often observed that the surface tension of polyelectrolyte solutions is similar to that of water, even though the polyelectrolyte possesses a higher propensity at the surface than in the bulk. ${ }^{42}$ The absence of an effect on the surface tension can be explained by the fact that the polyelectrolyte solution also contains counterions that often strongly interact with water and that thus have an opposing effect on the surface tension. The advantage of VSFG in detecting the surface accumulation of HA is that this technique is highly selective in probing HA and not affected by the other properties of the solution.

The spectral changes in the $\mathrm{CH}$ region indicate that, after diffusion to the surface, a rearrangement of the polymers takes place. The peak of the methylene group $\left(\nu_{\mathrm{CH}_{2}, \mathrm{SS}}\right)$ overlapping with the Fermi resonance of the methyl group at $2940 \mathrm{~cm}^{-1}$ appears first, whereas at later times, the signal of the symmetric stretch vibration of the methyl group at $2880 \mathrm{~cm}^{-1}$ becomes dominant (see Figure S6 in the Supporting Information). The observation of signals of $-\mathrm{CH}_{2} /-\mathrm{CH}_{3}$ suggests that the polymer backbone is aligned along the interfacial plane, with 
hydrophobic groups pointing into the air and negatively charged groups buried in the water and thus pointing toward the bulk. ${ }^{43,44}$ This observation is in line with the formation of so-called train segments of polymers at interfaces. ${ }^{44,45}$

Effect of Hyaluronan Molecular Weight on Its Accumulation at the Surface. To study the effect of the molecular weight of the polymers on the surface accumulation, we also measured the adsorption kinetics of hyaluronic acid solutions with a high molecular weight $\left(\mathrm{HA}_{\mathrm{HMW}} \sim 1.5-1.8\right.$ $\mathrm{MDa})$ at different concentrations, in a time frame of $0-240$ min. We observe in Figure $3 \mathrm{a}$ that the $\mathrm{HA}_{\mathrm{HMW}}$ solution shows a similar spectrum as a neat water-air interface. In contrast to $\mathrm{HA}_{\text {LMW }}$, the spectra are observed to stay similar over time. Therefore, we conclude that $\mathrm{HA}_{\mathrm{HMW}}$ molecules do not adsorb to the water surface, even at a concentration of $4.5 \mathrm{mg} / \mathrm{mL}$ (Figure $3 \mathrm{~b}$ ). Similar results were obtained at concentrations of 2.5 and $3.5 \mathrm{mg} / \mathrm{mL}$, as shown in the Supporting Information (Figure S7).

The large difference in observed surface accumulation between $\mathrm{HA}_{\mathrm{LMW}}$ and $\mathrm{HA}_{\mathrm{HMW}}$ must be primarily due to a kinetic effect as the thermodynamics of these solutions are highly similar. Here, we cannot exclude the formation of intramolecular aggregates, but we can exclude that this would cause the observed difference in kinetics. The tendency to form intramolecular aggregates will be quite similar for LMW and HMW hyaluronan, as the two polymers are composed of exactly the same disugar units and both have chain lengths that are much longer than their persistence length. Hence, if there would be intramolecular aggregation, this would occur similarly for $\mathrm{HA}_{\mathrm{LMW}}$ and $\mathrm{HA}_{\mathrm{HMW}}$. The difference in kinetics for the surface accumulation of $\mathrm{HA}_{\mathrm{LMW}}$ and $\mathrm{HA}_{\mathrm{HMW}}$ likely follows from the following two effects. In the first place, $\mathrm{HA}_{\mathrm{LMW}}$ diffuses faster than $\mathrm{HA}_{\mathrm{HMW}}$ due to its 10 times shorter chain length. A second effect that becomes important at high concentrations is the overlap and entanglement of $\mathrm{HA}_{\mathrm{HMw}}$ molecules, which strongly restricts diffusive motion. ${ }^{46}$ The overlap concentration of $\mathrm{HA}_{\mathrm{LMW}}$ of $\sim 10 \mathrm{mg} / \mathrm{mL}$ is much higher than the overlap concentration of $\sim 1.5-2 \mathrm{mg} / \mathrm{mL}$ of $\mathrm{HA}_{\mathrm{HMW}}{ }^{47,48}$ Therefore, the shorter polymer chains have much higher mobility than $\mathrm{HA}_{\mathrm{HMw}}$ molecules. To support this argument further, we also measured the dynamics of a $\mathrm{HA}_{\mathrm{HMW}}$ solution with an even higher concentration of $5.5 \mathrm{mg} / \mathrm{mL}$. We find that very long waiting times $\mathrm{HA}_{\mathrm{HMW}}$ does get adsorbed to the surface and shows the same vibrational features as $\mathrm{HA}_{\mathrm{LMW}}$ (Supporting Information Figure S8). This finding indicates that $\mathrm{HA}_{\mathrm{LMW}}$ also tends to accumulate at the surface, like $\mathrm{HA}_{\mathrm{LMW}}$, only the rate at which this happens is much lower.

Effect of $\mathrm{pH}$ on the Surface Accumulation of Hyaluronan. In Figure 4, we show the $\operatorname{Im}\left[\chi^{(2)}\right]$ spectra of a $\mathrm{HA}_{\mathrm{LMW}}$ solution in the region of the $\mathrm{OH}$ stretch vibrations measured at $\mathrm{pH} 2$ and a $\mathrm{NaCl}$ concentration of $150 \mathrm{mM}$. This $\mathrm{pH}$ value is below the isoelectric point of HA $(2.5),{ }^{49}$ meaning that at this $\mathrm{pH}$ the $\mathrm{HA}$ polymers are no longer negatively charged. Surprisingly very little change between the spectra measured at different waiting times can be observed in comparison to water. The rise of the $\mathrm{CH}$ peaks at later delay times shows that hyaluronan comes to the surface but quite delayed and to a much lesser extent than at $\mathrm{pH} 7.4$ (see Figure 2 ). It is also seen that the arrival of hyaluronan at the surface does not lead to a change of the sign of the water $\mathrm{OH}$ band. This latter observation can be explained by the fact that at these low $\mathrm{pH}$ values $90 \%$ of all carboxylate anion groups of hyaluronan, ${ }^{15}$ which has an isoelectric point of 2.5 , ${ }^{49}$ will be

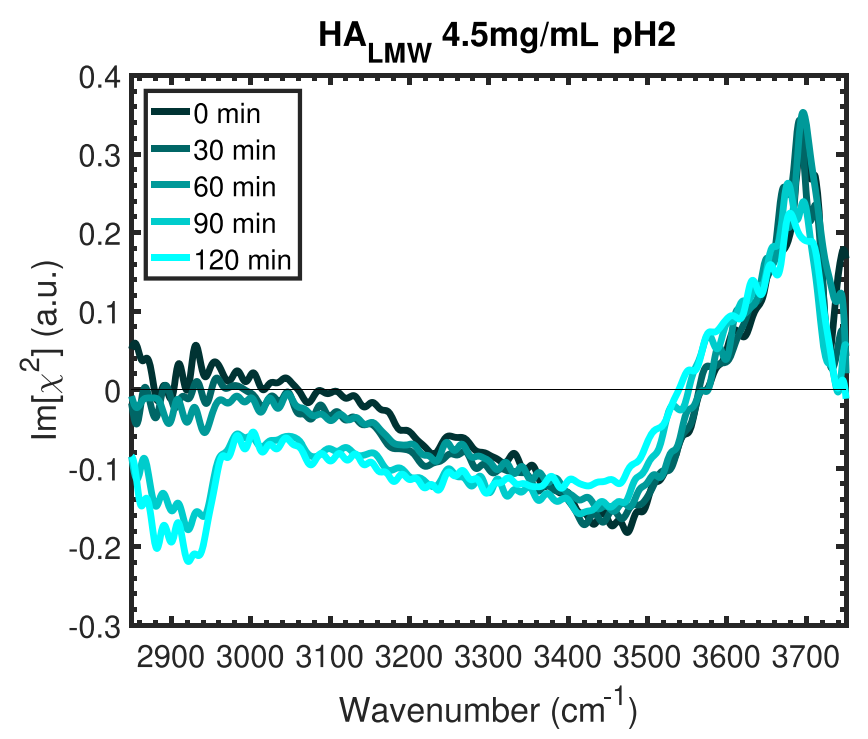

Figure 4. $\operatorname{Im}\left[\chi^{(2)}\right]$ spectra of $\mathrm{HA}_{\mathrm{LMW}}$ solutions with a concentration of $4.5 \mathrm{mg} / \mathrm{mL}$ at $\mathrm{pH} 2$ in the time frame of $0-90 \mathrm{~min}$.

protonated. Hence, hyaluronan will carry only $10 \%$ negative charge, and the accumulation of hyaluronan at the surface does not induce a change of the orientation of the water $\mathrm{OH}$ groups from a net orientation to the bulk to a net orientation to the surface. ${ }^{15}$

To study the $\mathrm{pH}$ dependence of the surface accumulation of HA in more detail, we performed intensity VSFG measurements of hyaluronan at different $\mathrm{pH}$ values in the frequency region of the carboxylate anion and carbonyl vibrations of hyaluronan $\left(1300-1900 \mathrm{~cm}^{-1}\right)$. In Figure 5, we present intensity VSFG measurements of $4.5 \mathrm{mg} / \mathrm{mL} \mathrm{HA}_{\mathrm{LMW}}$ solutions in the frequency region of $1300-1900 \mathrm{~cm}^{-1}$ measured at different $\mathrm{pH}$ values in a time frame of $0-120 \mathrm{~min}$. The $\mathrm{pH}$ was adjusted by adding $\mathrm{HCl}$ or $\mathrm{NaOH}$ to the solution. At all $\mathrm{pH}$ values, the $\mathrm{NaCl}$ concentration was $150 \mathrm{mM}$. Figure 5a shows the intensity VSFG spectra of a HA solution with $\mathrm{pH} 2$. The spectra at different times all show a broad band around 1650 $\mathrm{cm}^{-1}$, which can be assigned to the bending mode of water. The observed spectrum is similar to the spectrum observed in previous intensity VSFG measurements of the neat water surface (see also Figure S9). ${ }^{50,51}$ At $\mathrm{pH} 4.5$ (Figure 5b), we observe the same spectrum as at $\mathrm{pH}$ 2. For HA solutions with a $\mathrm{pH}$ above 7 (Figure 5c,d), two prominent features appear in the spectra at 1420 and $1720 \mathrm{~cm}^{-1}$. We assign the narrow peak at $1420 \mathrm{~cm}^{-1}$ to the symmetric stretch vibration of the carboxylate anion $\left(\nu_{\mathrm{ss}, \mathrm{COO}^{-}}\right)$of $\mathrm{HA}$, and the narrow peak at $1720 \mathrm{~cm}^{-1}$ to the carbonyl stretch vibration of the carboxylic acid group $(-\mathrm{COOH})$ of HA. ${ }^{52,53}$ In view of the bulk $\mathrm{p} K_{\mathrm{a}}$ of $\mathrm{HA}$, the presence of protonated carboxyl groups is unexpected at $\mathrm{pH}$ values above 6 . However, in previous work, it was found that the degree of acid dissociation at the surface can differ strongly from the degree of acid dissociation in the bulk. ${ }^{52,54}$ We observe that at $\mathrm{pH}=12$ (Figure $5 \mathrm{c}$ ) the relative intensity of the $-\mathrm{COOH}$ band is reduced compared to $\mathrm{pH}=7$, indicating a further deprotonation of hyaluronan at the interface. This $\mathrm{pH}$ dependence supports the assignment of the peak at $1720 \mathrm{~cm}^{-1}$ to the carbonyl stretch vibrations of the protonated carboxylic acid. Nevertheless, it is surprising that the feature at $1720 \mathrm{~cm}^{-1}$ does not vanish completely at $\mathrm{pH} 12$, since one would expect $\mathrm{HA}_{\mathrm{LMW}}$ to be completely deprotonated at this high $\mathrm{pH}$, even at the surface. It could be that the surface 

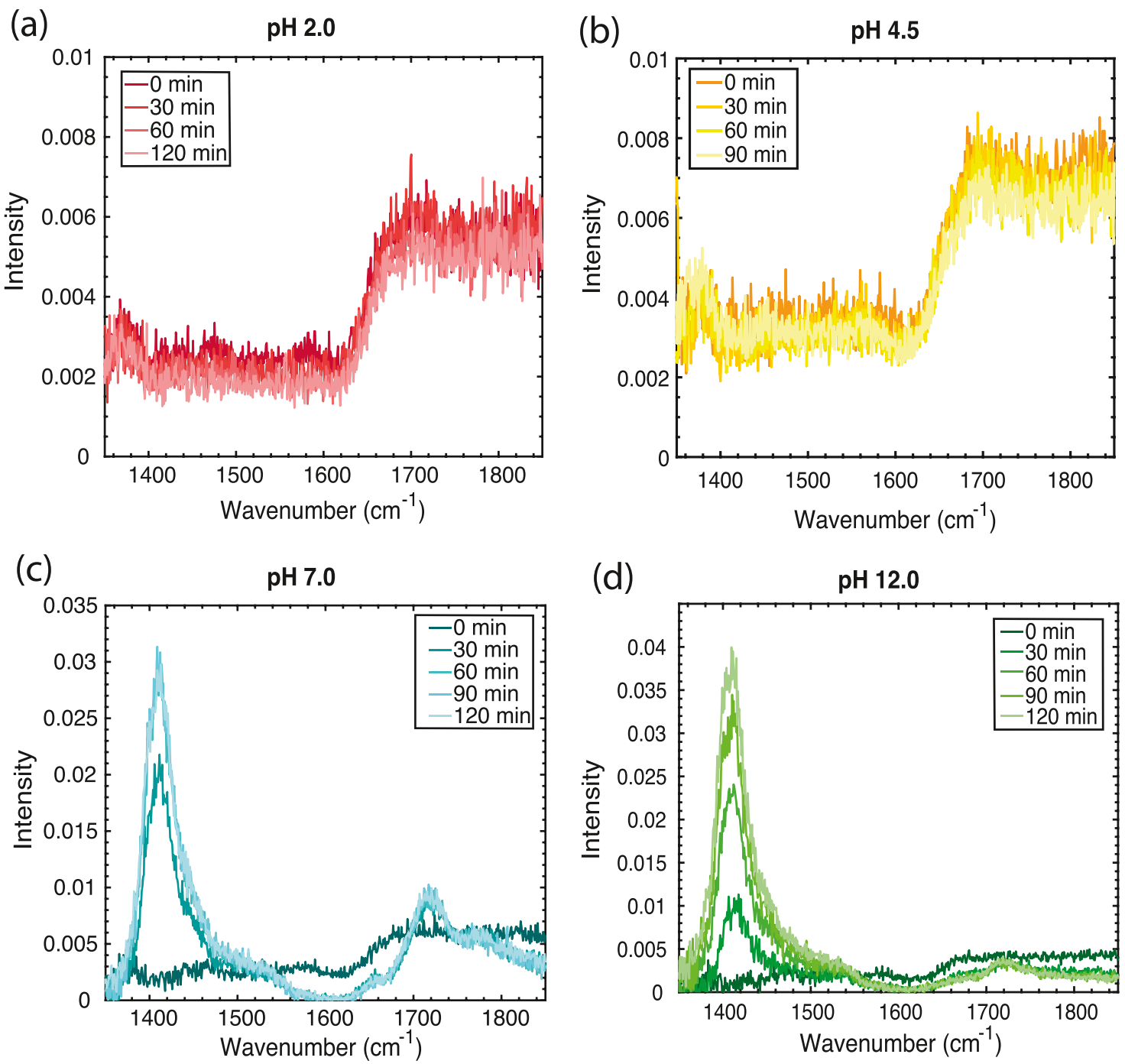

Figure 5. Intensity SFG spectra of $4.5 \mathrm{mg} / \mathrm{mL} \mathrm{HA}_{\mathrm{LMW}}$ solutions with different $\mathrm{pH}$ values of (a) 2 (red), (b) 4.5 (yellow), 7 (blue), and (d) 12 (green). The $\mathrm{pH}$ was adjusted using $\mathrm{HCl}$ and $\mathrm{NaOH}$, while the salt concentration was constant at $150 \mathrm{mM}$ of $\mathrm{NaCl}$ over all measurements.

contains a small amount of contaminations that gives rise to a small signal at $1720 \mathrm{~cm}^{-1}$ at all $\mathrm{pH}$ values, and that forms the only contribution to this signal at $\mathrm{pH} 12$.

To quantify the effect of the solution $\mathrm{pH}$ on the surface accumulation of $\mathrm{HA}_{\mathrm{LMW}}$ with a concentration of $4.5 \mathrm{mg} / \mathrm{mL}$, we plot in Figure 6 the sum of the band areas below the $\mathrm{COOH}$ and $\mathrm{COO}-$ peaks as a function of the $\mathrm{pH}$. The band areas were extracted from a fitting procedure using Lorentzian curves centered at 1720 and $1420 \mathrm{~cm}^{-1}$. The fitting procedure is illustrated in Figure S10 of the Supporting Information. Figure 6 clearly shows that the surface propensity strongly depends on the $\mathrm{pH}$. For $\mathrm{HA}_{\mathrm{LMW}}$ solutions at low $\mathrm{pH}$, the bands at 1720 and $1420 \mathrm{~cm}^{-1}$ are absent while increasing the $\mathrm{pH}$ to 7 leads to a strong increase of the summed area of these bands, indicating that $\mathrm{HA}_{\mathrm{LMW}}$ molecules accumulate at the surface.

Previous measurements on poly(acrylic acid) (PAA) at water-air and water-oil interface also showed a high sensitivity of the degree of accumulation at the surface on the $\mathrm{pH}$ value. ${ }^{25,55-57}$ For PAA solutions, it was observed that increasing the bulk $\mathrm{pH}$ led to the depletion of polymers from the surface because of the relative increase of carboxylate anion groups with respect to $\mathrm{COOH}$. In this context, it is remarkable and surprising that in the case of hyaluronan, depletion from the surface occurs upon lowering the $\mathrm{pH}$ value. A possible explanation for this anomalous behavior of $\mathrm{HA}_{\mathrm{LMW}}$ lies in the specific interchain interactions of $\mathrm{HA}$ that arises from low $\mathrm{pH}$ values. A special property of aqueous solutions of $\mathrm{HA}$ is that they form an elastic hydrogel near a $\mathrm{pH}$ value of $2.5 .^{15}$ In a recent study, we showed that the formation of the hydrogel finds its origin in an enhanced interchain interaction of the HA polymer chains, in particular in the formation of interchain hydrogen bonds between amide groups and carboxylate anion groups, and between amide groups and carboxylic acid groups. ${ }^{15}$ At high $\mathrm{pH}$ values, these interchain hydrogen bonds do not form because the polymer chains are strongly negatively charged and therefore repel each other. When the $\mathrm{pH}$ is lowered, carboxylate anion groups get protonated and the Coulombic repulsion between the polymers is decreased. As a result, the hyaluronan polymer chains will form interchain hydrogen bonds that continuously break and reform. This dynamic sticking of hyaluronan polymers will strongly decrease their rate of diffusion, which provides an explanation why hyaluronan does not come to the surface even within a few hours at $\mathrm{pH}$ values $<7$. Here, it is important to mention that at low $\mathrm{pH}$ values $<2.5 \mathrm{HA}$ can also form aggregates, which can cause a depletion from the surface. ${ }^{15}$ In our measurements, we 


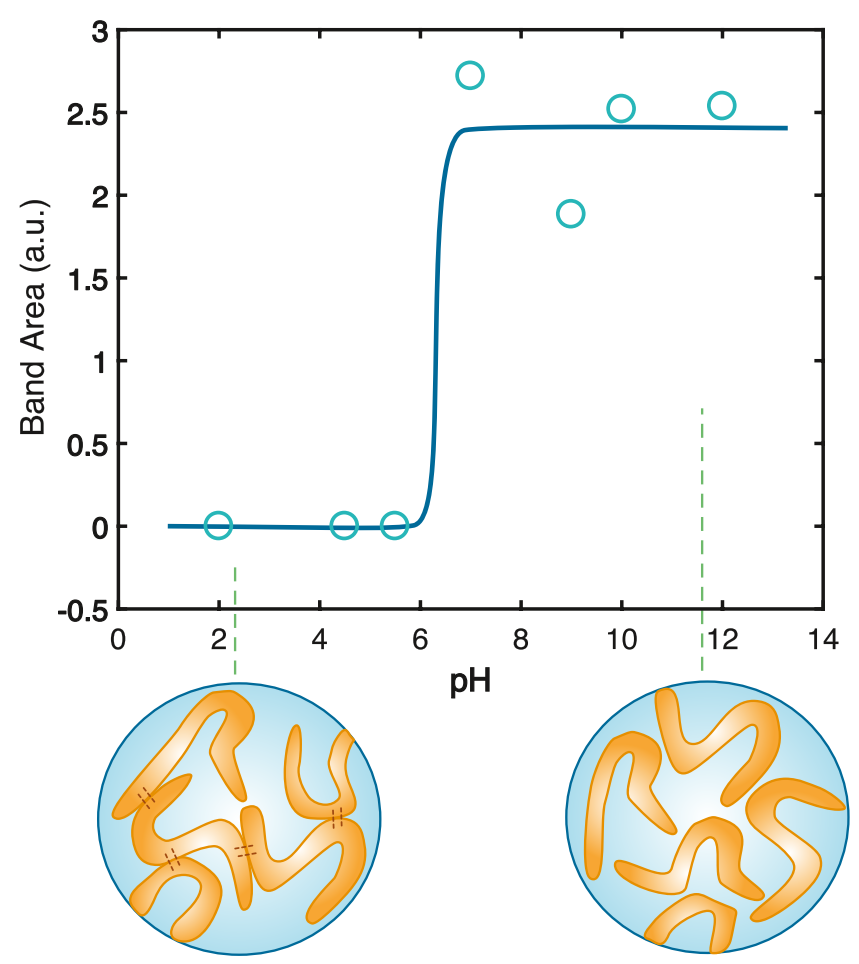

Figure 6. Sum of the band areas of the $\mathrm{COOH}$ and the $\mathrm{COO}-$ peak of a $4.5 \mathrm{mg} / \mathrm{mL} \mathrm{HA}_{\mathrm{LMW}}$ solution at different $\mathrm{pH}$ values. The band areas were extracted from a fitting procedure using two Lorentzian curves. The solid line is a guide to the eye. Below the plot: Schematic pictures of hyaluronan polymers in solution in two different $\mathrm{pH}$ regimes, showing that for low $\mathrm{pH}$ value $\mathrm{HA}$ polymer chains have enhanced interchain interaction, while diffusing freely in the solvent for high $\mathrm{pH}$ values.

can find that also at $\mathrm{pH}$ values of 4.5 and 5.5, $\mathrm{HA}_{\mathrm{LMw}}$ is absent from the surface. Therefore, we suggest that the formation of interchain hydrogen bonds between the HA molecules is the main reason for the depletion of HA from the surface. At the bottom of Figure 6, we show a schematic drawing of the structure of HA polymer chains in the two different $\mathrm{pH}$ regimes. The anomalous $\mathrm{pH}$ dependence of the accumulation at the surface of hyaluronan can thus be well explained from the special property of hyaluronan to show enhanced interchain interactions at low $\mathrm{pH}$ values.

\section{CONCLUSIONS}

We used vibrational sum-frequency generation (VSFG) and heterodyne-detected VSFG (HD-VSFG) to study the dependence of the surface accumulation and surface structure of hyaluronan polymers on the molecular weight and concentration of the polymers and the $\mathrm{pH}$ of the solution. The VSFG measurements show that at $1 \mathrm{mg} / \mathrm{mL}$, low-molecular-weight $(\sim 150 \mathrm{kD})$ hyaluronan accumulates at the surface within a few hours, rendering the surface negatively charged due to the presence of carboxylate anion groups in hyaluronan polymers. This rate strongly increases when the concentration of lowmolecular-weight hyaluronan increases. High-molecular-weight $(\sim 1000 \mathrm{kD})$ hyaluronan does not accumulate at the surface within hours, which we explain from the much lower rate of diffusion of these polymers. The difference in observed surface accumulation between $\mathrm{HA}_{\mathrm{LMW}}$ and $\mathrm{HA}_{\mathrm{HMW}}$ is thus primarily due to kinetic effects. We find that the surface accumulation of hyaluronan strongly depends on the $\mathrm{pH}$ of the solution. A lowering of the $\mathrm{pH}$ of the solvent strongly decreases the degree of accumulation of hyaluronan at the surface, which we explain from the enhanced interchain interactions of the hyaluronan polymer chains and the consequent decrease of the rate of diffusion of the polymer chains. The present results show that the migration of hyaluronan to the surface shows a strong and anomalous dependence on the polymer molecular weight and the properties of the solution. These results can aid the understanding of the behavior of hyaluronan at other aqueous interfaces than the water-air interface studied here, in particular, interfaces that are relevant for lubrication. It would be highly interesting to investigate the migration behavior and surface properties of hyaluronan also for other aqueous interfaces, and for varying solution properties, e.g., to study the effect of different salts on the rate of surface accumulation. We hope that the present work will stimulate experimental and theoretical work in this direction.

\section{ASSOCIATED CONTENT}

\section{Supporting Information}

The Supporting Information is available free of charge at https://pubs.acs.org/doi/10.1021/acs.macromol.1c00366.

Schematic of the custom-built sample cell made from Teflon; effect of the salt concentration in the solvent on the accumulation of hyaluronan at the surface (Figure $\mathrm{S} 1) ; \operatorname{Im}\left[\chi^{(2)}\right]$ spectra of $\mathrm{HA}_{\mathrm{LMW}}$ solutions with a concentration of $4.5 \mathrm{mg} / \mathrm{mL}$ with $\mathrm{pH} 7$ and no $\mathrm{NaCl}$ added (Figure S2); intensity SFG spectra of $4.5 \mathrm{mg} / \mathrm{mL}$ $\mathrm{HA}_{\text {LMW }}$ solutions with different $\mathrm{NaCl}$ concentrations (Figure S3); surface tension measurements of $\mathrm{HA}_{\mathrm{LMW}}$ at different concentrations and $\mathrm{pH} 2$ (Figures $\mathrm{S} 4$ and S5); enlarged $\operatorname{Im}\left[\chi^{(2)}\right]$ spectra of the $\mathrm{CH}$ vibrations of a 4.5 $\mathrm{mg} / \mathrm{mL} \mathrm{HA} \mathrm{HMW}_{\text {LM }}$ solution (Figure $\mathrm{S} 6$ ); $\operatorname{Im}\left[\chi^{(2)}\right]$ spectra of $\mathrm{HA}_{\mathrm{HMW}}$ solutions with concentrations of 2.5 and 3.5 $\mathrm{mg} / \mathrm{mL}$ (Figure S7); $\operatorname{Im}\left[\chi^{(2)}\right]$ spectra of $5.5 \mathrm{mg} / \mathrm{mL}$ $\mathrm{HA}_{\mathrm{HMW}}$ solutions in a time frame of $0-300 \mathrm{~min}$; $\mathrm{HA}_{\mathrm{HMW}}$ accumulates at the solution surface within at very long waiting times over $240 \mathrm{~min}$ (Figure S8); intensity VSFG spectra of the water bending mode (Figure S9); and fitting procedure of the VSFG spectra of $\mathrm{HA}_{\mathrm{LMW}}$ at different $\mathrm{pH}$ values (Figure S10) (PDF)

\section{AUTHOR INFORMATION}

\section{Corresponding Authors}

Carolyn J. Moll - Amolf, 1098 XG Amsterdam, The Netherlands; 이이.org/0000-0001-6041-5898; Email: cmoll@amolf.nl

Huib J. Bakker - Amolf, 1098 XG Amsterdam, The Netherlands; ○ orcid.org/0000-0003-1564-5314; Phone: +31 (0)20 754 7100; Email: H.Bakker@amolf.nl; Fax: +31(0)20754 7290

\section{Authors}

Giulia Giubertoni - Amolf, 1098 XG Amsterdam, The Netherlands; Van 't Hoff Institute for Molecular Sciences, University of Amsterdam, 1098 XH Amsterdam, The Netherlands; 이이.org/0000-0002-3417-4987

Lennard van Buren - Amolf, 1098 XG Amsterdam, The Netherlands; Department of Bionanoscience, Kavli Institute of Nanoscience Delft, Delft University of Technology, 2629 HZ Delft, The Netherlands

Jan Versluis - Amolf, 1098 XG Amsterdam, The Netherlands 
Gijsje H. Koenderink - Amolf, 1098 XG Amsterdam, The Netherlands; Department of Bionanoscience, Kavli Institute of Nanoscience Delft, Delft University of Technology, $2629 \mathrm{HZ}$ Delft, The Netherlands; ○ orcid.org/0000-0002-7823-8807

Complete contact information is available at: https://pubs.acs.org/10.1021/acs.macromol.1c00366

\section{Notes}

The authors declare no competing financial interest.

\section{ACKNOWLEDGMENTS}

This work is part of the research program of the Netherlands Organization for Scientific Research (NWO) and was performed at the research institute AMOLF. This work is part of the industrial partnership program Hybrid Soft Materials that is carried out under an agreement between Unilever Research and the Netherlands Organisation for Scientific Research (NWO).

\section{REFERENCES}

(1) Onishi, A.; St Ange, K.; Dordick, J. S.; Linhardt, R. J. Heparin and anticoagulation. Front. Biosci. 2016, 21, 1372-1392.

(2) Kogan, G.; Soltes, L.; Stern, R.; Gemeiner, P. Hyaluronic acid: a natural biopolymer with a broad range of biomedical and industrial applications. Biotechnol. Lett. 2006, 29, 17-25.

(3) Zhang, Z.; Christopher, G. F. The nonlinear viscoelasticity of hyaluronic acid and its role in joint lubrication. Soft Matter 2015, 11, 2596-2603.

(4) Chaudhuri, O.; Gu, L.; Klumpers, D.; Darnell, M.; Bencherif, S. A.; Weaver, J. C.; Huebsch, N.; Lee, H. P.; Lippens, E.; Duda, G. N.; Mooney, D. J. Hydrogels with tunable stress relaxation regulate stem cell fate and activity. Nat. Mater. 2016, 15, 326-334.

(5) Litwiniuk, M.; Krejner-Bienias, A.; Speyrer, M.; Gauto, A.; Grzela, T. Hyaluronic Acid in Inflammation and Tissue Regeneration. Wounds 2016, 28, 78-88.

(6) Toole, B. P. Hyaluronan: from extracellular glue to pericellular cue. Nat. Rev. Cancer 2004, 4, 528-539.

(7) Tian, X.; Azpurua, J.; Hine, C.; Vaidya, A.; Myakishev-Rempel, M.; Ablaeva, J.; Mao, Z.; Nevo, E.; Gorbunova, V.; Seluanov, A. Highmolecular-mass hyaluronan mediates the cancer resistance of the naked mole rat. Nature 2013, 499, 346-349.

(8) Kwiecinski, J. J.; Dorosz, S. G.; Ludwig, T. E.; Abubacker, S.; Cowman, M. K.; Schmidt, T. A. The effect of molecular weight on hyaluronan's cartilage boundary lubricating ability e alone and in combination with proteoglycan 4. Osteoarthritis Cartilage 2011, 19, $1356-1362$.

(9) Florian Wieland, D. C.; Degen, P.; Zander, T.; Gayer, S.; Raj, A.; An, J.; Andra Dedinaite, P. C.; Willumeit-Römera, R. Soft Matter Effects of Molecular Weight and Ion Composition; Royal Society of Chemistry, 2016; Vol. 12, pp 729-740.

(10) Temple-wong, M. M.; Ren, S.; Quach, P.; Hansen, B. C.; Chen, A. C.; Hasegawa, A.; Lima, D. D. D.; Koziol, J.; Masuda, K.; Lotz, M. K.; Sah, R. L. Hyaluronan concentration and size distribution in human knee synovial fluid: variations with age and cartilage degeneration. Arthritis Res. Ther. 2016, 1-8.

(11) Singh, A.; Corvelli, M.; Unterman, S. A.; Wepasnick, K. A.; McDonnell, P.; Elisseeff, J. H. Enhanced lubrication on tissue and biomaterial surfaces through peptide-mediated binding of hyaluronic acid. Nat. Mater. 2014, 13, 988-995.

(12) Rah, M. J. A review of hyaluronan and its ophthalmic applications. Optometry 2011, 82, 38-43.

(13) Nichols, J. J.; Sinnott, L. T. Tear film, contact lens, and patientrelated factors associated with contact lens-related dry eye. Invest. Ophthalmol. Visual Sci. 2006, 47, 1319-1328.
(14) van Dam, E. P.; Giubertoni, G.; Burla, F.; Koenderink, G. H.; Bakker, H. J. Hyaluronan biopolymers release water upon $\mathrm{pH}$-induced gelation. Phys. Chem. Chem. Phys. 2020, 22, 8667-8671.

(15) Giubertoni, G.; Burla, F.; Martinez-Torres, C.; Dutta, B.; Pletikapic, G.; Pelan, E.; Rezus, Y. L.; Koenderink, G. H.; Bakker, H. J. Molecular Origin of the Elastic State of Aqueous Hyaluronic Acid. J. Phys. Chem. B 2019, 123, 3043-3049.

(16) Giubertoni, G.; Koenderink, G. H.; Bakker, H. J. Direct Observation of Intrachain Hydrogen Bonds in Aqueous Hyaluronan. J. Phys. Chem. A 2019, 123, 8220-8225.

(17) Burla, F.; Tauber, J.; Dussi, S.; van der Gucht, J.; Koenderink, G. H. Stress management in composite biopolymer networks. Nat. Phys. 2019, 15, 549-553.

(18) Chen, X.; Richter, R. P. Effect of calcium ions and $\mathrm{pH}$ on the morphology and mechanical properties of hyaluronan brushes. Interface Focus 2019, 9, No. 20180061.

(19) Balazs, E. A.; Cui, J. The story of hyaluronan putty. Bioact. Carbohydr. Diet. Fibre 2013, 2, 143-151.

(20) Weigel, P. H.; DeAngelis, P. L. Hyaluronan synthases: A decade-plus of novel glycosyltransferases. J. Biol. Chem. 2007, 282, 36777-36781.

(21) Martin-Alarcon, L.; Schmidt, T. A. Rheological effects of macromolecular interactions in synovial fluid. Biorheology 2016, 53, $49-67$.

(22) Vorvolakos, K.; Coburn, J. C.; Saylor, D. M. Dynamic interfacial behavior of viscoelastic aqueous hyaluronic acid: Effects of molecular weight, concentration and interfacial velocity. Soft Matter 2014, 10, 2304-2312.

(23) Ribeiro, W.; Mata, L.; Saramago, B. Effect of Concentration and Temperature on Surface Tension of Sodium Hyaluronate Saline Solutions. Langmuir 2007, 94, 7014-7017.

(24) Shen, Y. R. Surface properties probed by second-harmonic and sum-frequency generation. Nature 1989, 337, 519-525.

(25) Balzerowski, P.; Meister, K.; Versluis, J.; Bakker, H. J. Heterodyne-detected sum frequency generation spectroscopy of polyacrylic acid at the. Phys. Chem. Chem. Phys. 2015, 18, 2481-2487.

(26) Lu, X.; Zhang, C.; Ulrich, N.; Xiao, M.; Ma, Y. H.; Chen, Z. Studying Polymer Surfaces and Interfaces with Sum Frequency Generation Vibrational Spectroscopy. Anal. Chem. 2017, 89, 466489.

(27) $\mathrm{Hu}, \mathrm{D}$; Chou, K. C. Re-Evaluating the Surface Tension Analysis of Polyelectrolyte-Surfactant Mixtures Using Phase-Sensitive Sum Frequency Generation Spectroscopy. J. Am. Chem. Soc. 2014, 136, 15114-15117.

(28) Physicochemical Properties of Articular Cartilage. In Adult Articular Cartilage; Freeman, M. A. R., Eds.; Pitman Medical, 1979; pp 215-290.

(29) Ostroverkhov, V.; Waychunas, G. A.; Shen, Y. R. New information on water interfacial structure revealed by phase-sensitive surface spectroscopy. Phys. Rev. Lett. 2005, 94, No. 046102.

(30) Yamaguchi, S.; Tahara, T. Heterodyne-detected electronic sum frequency generation: "Up" versus "down" alignment of interfacial molecules. J. Chem. Phys. 2008, 129, No. 101102.

(31) Nihonyanagi, S.; Yamaguchi, S.; Tahara, T. Direct evidence for orientational flip-flop of water molecules at charged interfaces: A heterodyne-detected vibrational sum frequency generation study. $J$. Chem. Phys. 2009, 130, No. 204704.

(32) Shen, Y. R. Phase-Sensitive Sum-Frequency Spectroscopy. Annu. Rev. Phys. Chem. 2013, 64, 129-150.

(33) Moll, C. J.; Meister, K.; Kirschner, J.; Bakker, H. J. Surface Structure of Solutions of Poly(vinyl alcohol) in Water. J. Phys. Chem. B 2018, 122, 10722-10727.

(34) Superfine, R.; Huang, J. Y.; Shen, Y. R. Nonlinear optical studies of the pure liquid/vapor interface: Vibrational spectra and polar ordering. Phys. Rev. Lett. 1991, 66, 1066-1069.

(35) Tian, C. S.; Shen, Y. R. Isotopic dilution study of the water/ vapor interface by phase-sensitivesum-frequency vibrational spectroscopy. J. Am. Chem. Soc. 2009, 131, 2790-2791. 
(36) Chen, X.; Hua, W.; Huang, Z.; Allen, H. C. Interfacial water structure associated with phospholipid membranes studied by phasesensitive vibrational sum frequency generation spectroscopy. J. Am. Chem. Soc. 2010, 132, 11336-11342.

(37) Conboy, J. C.; Messmer, M. C.; Richmond, G. L. Dependence of alkyl chain conformation of simple ionic surfactants on head group functionality as studied by vibrational sum-frequency spectroscopy. $J$. Phys. Chem. B 1997, 101, 6724-6733.

(38) Cota, R.; Ottosson, N.; Bakker, H. J.; Woutersen, S. Evidence for Reduced Hydrogen-Bond Cooperativity in Ionic Solvation Shells from Isotope-Dependent Dielectric Relaxation. Phys. Rev. Lett. 2018, 120, No. 216001.

(39) Buchner, R. What can be learnt from dielectric relaxation spectroscopy about ion solvation and association? Pure Appl. Chem. 2008, 80, 1239-1252.

(40) Zhang, J.; Pelton, R. The dynamic behavior of poly(Nisopropylacrylamide) at the air/water interface. Colloids Surf., A 1999, $156,111-122$.

(41) Babak, V. G.; Skotnikova, E. A.; Lukina, I. G.; Pelletier, S.; Hubert, P.; Dellacherie, E. Hydrophobically associating alginate derivatives: Surface tension properties of their mixed aqueous solutions with oppositely charged surfactants. J. Colloid Interface Sci. 2000, 225, 505-510.

(42) Yim, H.; Kent, M.; Matheson, A.; Ivkov, R.; Satija, S.; Majewski, J.; Smith, G. S. Adsorption of poly(styrenesulfonate) to the air surface of water by neutron reflectivity. Macromolecules 2000, 33, 6134-6139.

(43) Hu, D.; Yang, Z.; Chou, K. C. Interactions of Polyelectrolytes with Water and Ions at Air/Water Interfaces Studied by PhaseSensitive Sum Frequency Generation Vibrational Spectroscopy. J. Phys. Chem. C 2013, 117, 15698-15703.

(44) Chen, Q.; Zhang, D.; Somorjai, G.; Bertozzi, C. R. Probing the surface structural rearrangement of hydrogels by sum-frequency generation spectroscopy. J. Am. Chem. Soc. 1998, 121, 446-447.

(45) Netz, R. R.; Andelman, D. Neutral and charged polymers at interfaces. Phys. Rep. 2003, 380, 1-95.

(46) van der Maarel, J. R. Introduction to Biopolymer Physics; World Scientific, 2007; pp 1-248.

(47) Lélu, S.; Pluen, A. Characterization of Composite Networks Made of Type I Collagen, Hyaluronic Acid and Decorin. Macromol. Symp. 2007, 256, 175-188.

(48) Borzacchiello, A.; Ambrosio, L. Network formation of low molecular weight hyaluronic acid derivatives. J. Biomater. Sci., Polym. Ed. 2001, 12, 307-316.

(49) Gatej, I.; Popa, M.; Rinaudo, M. Role of the $\mathrm{pH}$ on hyaluronan behavior in aqueous solution. Biomacromolecules 2005, 6, 61-67.

(50) Vinaykin, M.; Benderskii, A. V. Vibrational sum-frequency spectrum of the water bend at the air/water interface. J. Phys. Chem. Lett. 2012, 3, 3348-3352.

(51) Nagata, Y.; Hsieh, C. S.; Hasegawa, T.; Voll, J.; Backus, E. H.; Bonn, $\mathrm{M}$. Water bending mode at the water-vapor interface probed by sum-frequency generation spectroscopy: A combined molecular dynamics simulation and experimental study. J. Phys. Chem. Lett. 2013, 4, 1872-1877.

(52) Strazdaite, S.; Meister, K.; Bakker, H. J. Reduced Acid Dissociation of Amino-Acids at the Surface of Water. J. Am. Chem. Soc. 2017, 139, 3716-3720.

(53) Johnson, C. M.; Tyrode, E.; Baldelli, S.; Rutland, M. W. A Vibrational Sum Frequency Spectroscopy Study of the Liquid-Gas Interface of Acetic Acid-Water Mixtures: 1. Surface Speciation. J. Phys. Chem. B 2005, 321-328.

(54) Wellen, B. A.; Lach, E. A.; Allen, H. C. Surface $\mathrm{pK}_{\mathrm{a}}$ of octanoic, nonanoic, and decanoic fatty acids at the air-water interface: Applications to atmospheric aerosol chemistry. Phys. Chem. Chem. Phys. 2017, 19, 26551-26558.

(55) Beaman, D. K.; Robertson, E. J.; Richmond, G. L. Ordered polyelectrolyte assembly at the oil-water interface. Proc. Natl. Acad. Sci. U.S.A. 2012, 109, 3226-3231.
(56) Robertson, E. J.; Richmond, G. L. Molecular insights in the structure and layered assembly of polyelectrolytes at the oil/water interface. J. Phys. Chem. C 2014, 118, 28331-28343.

(57) Beaman, D. K.; Robertson, E. J.; Richmond, G. L. Metal ions: Driving the orderly assembly of polyelectrolytes at a hydrophobic surface. Langmuir 2012, 28, 14245-14253. 